Revista de

Contabilidade e

Organizações

www.rco.usp.br
DOI: http://dx.doi.org/10.11606/issn.1982-6486.rco.2020.164092
Journal of

Accounting and

Organizations

www.rco.usp.br

\title{
Role-play: desenvolvendo habilidades e competências do Ensino Embasado na Estrutura Conceitual
}

\author{
Role-play: developing skills of Framework-based Teaching
}

Patrícia de Souza Costa ${ }^{a}$, Jéssica Rayse de Melo Silva Ávilab, Dinah Vieira dos Santos ${ }^{\mathrm{a}}$; Fabiana Pereira da Cruz ${ }^{\mathrm{a}}$

${ }^{a}$ Universidade Federal de Uberlândia

${ }^{b}$ Universidade Federal de Viçosa

Palavras-chave

Role-play.

Ensino Embasado na Estrutura

Conceitual.

Taxonomia de Bloom.
Keywords

Role-play.

Framework-based Teaching.

Bloom's Taxonomy.

\begin{abstract}
Resumo
$\overline{\mathrm{O} \text { objetivo desta pesquisa é analisar a percepção dos estudantes quanto à utilidade }}$ da técnica role-play no desenvolvimento de habilidades e competências, requeridas ao profissional da área contábil no primeiro estágio do Ensino Embasado na Estrutura Conceitual. A percepção sobre o uso da técnica foi identificada por meio de levantamento e grupo focal com os estudantes matriculados na disciplina Contabilidade Introdutória. Os resultados sugerem que, na percepção dos estudantes, o role-play auxilia no desenvolvimento de habilidades e competências de todas as categorias do domínio cognitivo da Taxonomia de Bloom (Conhecimento, Compreensão, Aplicação, Análise, Síntese e Avaliação), superando as expectativas do Ensino Embasado na Estrutura Conceitual de desenvolvimento apenas das três primeiras categorias.
\end{abstract}

\begin{abstract}
The aim of this research is to analyze the students' perception regarding the usefulness of the role-play technique in the development of skills and competences required of the accounting professional in the first stage of the Framework-based Teaching. Students' perception of the use of the technique was identified through a survey and focus group with students enrolled in the Introductory Accounting discipline. The results suggest that, in the students' perception, role-play assisted in the development of skills and competences of all categories of the Bloom Taxonomy cognitive domain (Knowledge, Understanding, Application, Analysis, Synthesis and Evaluation), surpassing Framework-based Teaching expectations for development of the first three categories only.
\end{abstract}

\section{Implicações práticas}

$\mathrm{O}$ uso do role-play se mostrou útil para o desenvolvimento de habilidades e competências necessárias para a formação do profissional da área contábil. Além disso, os resultados podem ser úteis para o International Accounting Standards Board no aprimoramento do Ensino Embasado na Estrutura Conceitual.

Copyright (C) 2020 FEA-RP/USP. Todos os direitos reservados

\section{INTRODUÇÃO}

A abordagem do Ensino Embasado na Estrutura Conceitual (EEEC), iniciativa educacional do International Accounting Standards Board (IASB), divide a trajetória de ensino de um contador em três estágios: conscientização, compreensão e competência (Costa, Gomes, Braunbeck \& Santana, 2018). O primeiro estágio compreende as primeiras disciplinas de contabilidade financeira (introdutórias).

\footnotetext{
Autor correspondente: Tel. (34) 3219-4176

E-mail: patriciacosta_1@yahoo.com.br (P. de S. Costa); jessicarayse@hotmail.com (J. R. de M. S. Ávila); dinahvs29@gmail.com (D. V.dos Santos); fafapcruz20@hotmail.com (F. P. da Cruz)

Universidade Federal de Uberlândia. Av. João Naves de Ávila, 2121 - Santa Mônica, Uberlândia/MG - 38400902, Brasil.
} 
No primeiro estágio, o estudante deveria tomar consciência: 1) da existência de julgamentos e estimativas para aplicação das International Financial Reporting Standards (IFRS); 2) da necessidade de pensar conceitualmente por meio do conhecimento de trechos da Estrutura Conceitual; e 3) de princípios fundamentais das normas para reconhecer transações e eventos, classificar transações e aplicar os requerimentos normativos (Costa et al., 2018). Os estágios 2 e 3 se diferenciam do $1^{\circ}$ estágio, essencialmente, pelo desenvolvimento mais profundo das habilidades e competências para a realização de julgamentos e estimativas (Wells \& Tarca, 2014, Costa et al., 2018).

O EEEC sugere o uso de metodologias e estratégias de ensino que sejam capazes de auxiliar os estudantes no desenvolvimento do pensamento crítico, na associação entre a teoria e a prática, e a exercitar o uso de julgamentos e estimativas (Costa et al., 2018). Nesse sentido, o EEEC é condizente com as metodologias ativas de ensino, em que o estudante está envolvido na sua aprendizagem e o professor é um facilitador e não mais o detentor absoluto do conhecimento.

A estratégia de ensino role-play (jogo de papéis) pode auxiliar no desenvolvimento de habilidades e competências requeridas no estágio 1 da abordagem EEEC, principalmente, a relacionar teoria e prática e a ter uma visão prática do processo de tomada de decisões. Entretanto, não foram encontradas pesquisas que avaliem a eficácia dessa estratégia no alcance dos objetivos do EEEC.

Assim, o objetivo deste estudo é analisar a percepção dos estudantes quanto à utilidade da técnica roleplay no desenvolvimento de habilidades e competências, requeridas ao profissional da área contábil no primeiro estágio do Ensino Embasado na Estrutura Conceitual.

A pesquisa em questão foi aplicada em um curso de Ciências Contábeis de uma universidade pública mineira em 2017 e 2018. O instrumento utilizado na coleta de dados foi adaptado de Weil, Oyelere, Yeoh e Firer (2001) e de Costa et al. (2018) com o intuito de comparação dos resultados desta pesquisa com aqueles encontrados pelos autores para a estratégia de caso para ensino e, também, pela análise das habilidades e competências desenvolvidas à luz da Taxonomia de Bloom.

Os principais resultados sugerem que a aplicação do role-play é efetiva no alcance dos objetivos propostos pelo EEEC para o estágio 1, e que as maiores ocorrências de habilidades e competências aprimoradas estão localizadas nas mais altas categorias do Domínio Cognitivo, especialmente, a de Síntese, o que pode denotar a efetividade dessa técnica na consecução dos objetivos de aprendizagem. Além disso, por meio do uso dessa técnica, foi possível abranger todas as categorias do Domínio Cognitivo, no que tange aos estágios 1, 2 e 3 do EEEC. Por fim, observou-se que no início do curso, é possível desenvolver atividades que possam atingir essas categorias mais altas.

O estudo contribui com a avaliação da utilidade da técnica role-play no desenvolvimento de habilidades e competências requeridas no estágio 1 do EEEC, relevantes à formação do profissional contábil. Além disso, o estudo pode representar um 'termômetro' sobre a eficácia dessa técnica no ensino da contabilidade no início do curso, possibilitando uma ampliação das discussões acerca do uso de metodologias ativas no processo de ensinoaprendizagem.

Ademais, as disciplinas iniciais do curso, primeiro estágio do EEEC, principiarão o discente na Ciência Contábil, representando, portanto, base essencial para o aprendizado das demais disciplinas (Oliveira et al., 2016). Nessas disciplinas, os estudantes tomarão consciência de conceitos e terminologias que serão utilizados no decorrer de todo o curso, sendo o primeiro ano do estudo de contabilidade, segundo a Accounting Education Change Commission, bem crítico e relevante (Geiger \& Ogilby, 2000). Oliveira, Costa, Botinha e Tavares (2016), inclusive, acompanharam 63 estudantes ao longo do curso de Ciências Contábeis e identificaram que o desempenho desses estudantes nas disciplinas iniciais do curso influenciou seu desenvolvimento nas disciplinas subsequentes. Assim, estudar o primeiro estágio do EEEC pode trazer contribuições para estudantes, docentes e instituições de ensino.

\section{PLATAFORMA TEÓRICA}

A aprendizagem ativa tem se destacado por envolver abordagens e estratégias mais discursivas e colaborativas, nas quais os estudantes têm tarefas de pensamento de ordem superior, como análise, síntese e avaliação, além da resolução de problemas que demandam leitura, escrita, conversação e até mesmo a própria atuação (Mclaughlan \& Kirkpatrick, 2004). Dentre as estratégias tem-se o role-play que, além de retirar os estudantes da posição passiva de aprendizagem, ainda desenvolve a empatia, aumenta o interesse, a compreensão e a integração dos estudantes com o conteúdo apresentado (Souza \& Casa Nova, 2017). 
Por meio dessa técnica, os estudantes podem aprender desempenhando papéis próprios da sua realidade profissional, mas que, para isso, "é fundamental que cada elemento assuma integralmente seu papel, isto é, comporte-se como tal, defenda as posições próprias daquele papel, procure ter as reações e atitudes características daquele personagem" (Masetto, 2003, p. 122). Isso pode auxiliar no desenvolvimento de habilidades e atitudes dos estudantes (Masetto, 2003).

A participação dos estudantes é uma das vantagens do role-play, pois aumenta o nível de retenção e o interesse dos estudantes (Richardson \& Kleiner, 1992). Para esses autores, o role-play auxilia os estudantes a ganhar confiança, uma vez que a aproximação da realidade no ambiente de aprendizagem, onde têm a oportunidade de conhecer soluções alternativas, pode torná-los mais seguros diante de uma situação real quando essa ocorrer. Além disso, o role-play exige esforço de estudantes e docentes, os quais podem ser induzidos a achar que o esforço necessário excede o benefício do aprendizado.

Para o ensino contábil, Souza e Casa Nova (2017) aplicaram a estratégia do role-play com estudantes da disciplina de Contabilidade e Análise de Balanço, os quais assumiram papéis de agentes envolvidos no caso real de insolvência da companhia Varig. As percepções dos discentes foram avaliadas por meio de um focus group, em que foi possível identificar um nível favorável de satisfação, principalmente, no desenvolvimento de habilidades ligadas aos aspectos emocionais. As autoras identificaram aspectos negativos referentes ao tempo dispendido e à motivação.

Kern (2001) utilizou o role-play na primeira semana do curso de contabilidade, ao levar os estudantes a simularem transações para iniciar um negócio e assumirem papéis de responsáveis por registro contábil. Os resultados indicam que o role-play ajudou os estudantes a entenderem melhor o material quando comparado aos da aula expositiva. Além disso, os estudantes que participaram do role-play tiveram um desempenho melhor em um exame aplicado quatro semanas após a aula.

Souza et al. (2013) verificaram as habilidades desenvolvidas e a eficiência no aprendizado com base na visão do discente. Os resultados obtidos por meio do focus group sugerem que o role-play contribuiu para o desenvolvimento do senso crítico, da visão sob diferentes pontos de vista, da comunicação e do trabalho em equipe.

\subsection{Role-play, Ensino Embasado na Estrutura Conceitual e Taxonomia de Bloom}

A adoção das IFRS tornou evidente a demanda por um processo de ensino-aprendizagem que fosse capaz de preparar o estudante para a nova realidade do profissional de contabilidade (Costa et al., 2018). Nessa nova realidade, o contador precisa ser dotado de habilidades e competências que o permitam atuar em um ambiente profissional dinâmico e complexo.

Nesse sentido, o IASB iniciou, em 2005, a preparação de materiais de ensino gratuitos que pudessem inspirar as instituições de ensino a reformularem seus programas educacionais de contabilidade. Uma das iniciativas do IASB foi a proposição da abordagem Ensino Embasado na Estrura Conceitual (EEEC) ou framework-based approach (Wells, 2011).

O EEEC fundamenta-se no fato de que as IFRS são normas baseadas em princípios, com elevado grau de subjetividade e que demandam capacidade de abstração e julgamento profissional para interpretá-las e aplicá-las (Wells, 2011, Costa et al., 2018). A proposta do EEEC, portanto, é que o ensino de contabilidade parta do geral para o específico, iniciando na compreensão da Estrutura Conceitual, já que essa é a base consistente sobre a qual as IFRS estão fundamentadas, e progredindo para as especificidades de tratamento contidas em cada norma.

A aplicação da abordagem EEEC é adequada em qualquer momento do curso de contabilidade, porém a ideia é que o conteúdo seja trabalhado de forma progressiva (Wells, 2011), o que culmina na proposição de três estágios hierárquicos para ensino, quais sejam: conscientização; compreensão e a competência (Costa et al., 2018).

O primeiro estágio, “conscientização", deve ser desenvolvido nas primeiras disciplinas da formação profissional, por meio da utilização de trechos da estrutura conceitual que explicitem os objetivos e características qualitativas, as definições de elementos e os critérios de reconhecimento. O segundo estágio, "compreensão", é desenvolvido nas disciplinas intermediárias e se trata de um aprofundamento do conteúdo trabalhado no primeiro estágio, cujo objetivo é capacitar o estudante para realizar julgamentos e estimativas necessárias à aplicação da norma. O último estágio, "competência”, é desenvolvido nas disciplinas finais, anteriores à certificação profissional do estudante, e está relacionado à capacidade de integrar e fazer avaliação crítica do conteúdo aprendido (Costa et al., 2018). 
Em consonância com os objetivos do EEEC, tem-se empregado estratégias de ensino como o caso Barrick Gold Corporation (Goeld, 2013), cujo objetivo é trabalhar o conteúdo de goodwill, e o caso da Artisan Flowers (Mactavish \& Moore, 2016), cujo objetivo é trabalhar o conteúdo de leasing (IFRS 16). Alinhados ao desenvolvimento do domínio cognitivo da Taxonomia de Bloom, os casos são indicados para utilização no estágio 3 do EEEC.

Como exemplo prático, Costa et al. (2018) aplicaram o caso Open Safari para ensino do conteúdo de imobilizado e outros ativos não financeiros, em turmas do estágio 3 do EEEC, e concluíram que a aplicação da estratégia promoveu o desenvolvimento das habilidades e competências esperadas neste estágio. Para o roleplay não se encontrou, na literatura, aplicação em nenhum dos três estágios de aprendizagem, embora seja uma estratégia cujos objetivos parecem estar alinhados aos objetivos de aprendizagem do EEEC.

A Taxonomia de Bloom é um instrumento de planejamento, que auxilia na definição dos objetivos de aprendizagem a serem alcançados para o desenvolvimento de habilidades e competências cognitivas. Os objetivos de aprendizagem podem estar alinhados ao desenvolvimento do domínio cognitivo (aprender, desenvolver habilidades e atitudes) e do domínio afetivo (relacionado a sentimentos e posturas).

O estudo de Costa et al. (2018) buscou relacionar os objetivos de aprendizagem dos três estágios do EEEC com o domínio cognitivo, por meio de um questionário adaptado de Weil et al. $(1999 ; 2001)$, conforme mostra a Tabela 1. Segundo Costa et al. (2018), no primeiro estágio do EEEC (consciência), seriam desenvolvidas as três primeiras categorias do domínio cognitivo da Taxonomia de Bloom (conhecimento, compreensão e aplicação). No segundo estágio, seriam também desenvolvidas essas três categorias do domínio cognitivo somadas à categoria análise e, no terceiro estágio, seriam desenvolvidas todas as categorias do domínio cognitivo.

Tabela 1. Associação entre os estágios da EEEC e a Taxonomia de Bloom

\begin{tabular}{|c|c|c|c|c|}
\hline & $\begin{array}{c}\text { Categorias } \\
\text { Taxonomia de Bloom }\end{array}$ & \multicolumn{3}{|c|}{ Estágios do EEEC } \\
\hline \multirow{7}{*}{ 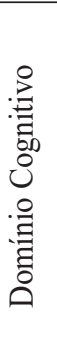 } & & 1 & 2 & 3 \\
\hline & 1 - Conhecimento & $\mathrm{x}$ & $\mathrm{x}$ & $\mathrm{X}$ \\
\hline & 2 - Compreensão & $\mathrm{x}$ & $\mathrm{x}$ & $\mathrm{x}$ \\
\hline & 3 - Aplicação & $\mathrm{x}$ & $\mathrm{x}$ & $\mathrm{x}$ \\
\hline & 4 - Análise & & $\mathrm{x}$ & $\mathrm{x}$ \\
\hline & 5 - Síntese & & & $\mathrm{x}$ \\
\hline & 6 - Avaliação & & & $\mathrm{x}$ \\
\hline
\end{tabular}

Fonte: adaptado de Costa et al. (2018).

Assim, para compreender a contribuição do role-play para o processo de aprendizagem no primeiro estágio do EEEC, à luz da Taxonomia de Bloom, a seguinte premissa foi adotada:

$\mathbf{P}_{1}$ : o uso da técnica role-play nas disciplinas iniciais de contabilidade (estágio 1 do EEEC) auxilia no desenvolvimento de habilidades e competências das três primeiras categorias do domínio cognitivo da Taxonomia de Bloom, conforme a percepção dos estudantes.

Costa et al. (2018) associou os estágios do EEEC apenas com o domínio cognitivo da Taxonomia de Bloom. Porém, as habilidades e competências relacionadas com o domínio afetivo da Taxonomia de Bloom podem ser desenvolvidas no processo de aplicação de metodologias ativas, e podem também estar associadas com os estágios do EEEC e/ou impulsionar o desenvolvimento daquelas do domínio cognitivo. Assim, a segunda premissa desta pesquisa é:

$\mathbf{P}_{2}$ : o uso da técnica role-play nas disciplinas iniciais de contabilidade (estágio 1 do EEEC) auxilia no desenvolvimento de habilidades e competências do domínio afetivo da Taxonomia de Bloom, conforme a percepção dos estudantes. 


\section{PROCEDIMENTO METODOLÓGICO}

\subsection{Aplicação da técnica role-play}

O role-play foi aplicado na atividade avaliativa denominada "Contabilidade em Cena" em três turmas que cursaram a disciplina Contabilidade Introdutória II (CI) no segundo semestre letivo de 2017, e nos dois semestres letivos de 2018. Ressalta-se que o curso de Ciências Contábeis da universidade objeto de estudo tem duração de cinco anos, sendo a disciplina CI ministrada no segundo semestre.

Para a realização da atividade, os discentes, no início do semestre, receberam as instruções da atividade, bem como uma lista de companhias abertas com, ao menos, duas firmas do mesmo setor de atividade para efeito de comparação e competição entre os grupos. Os discentes se reuniram em grupos de quatro a seis integrantes com o objetivo de escolher uma empresa da lista para iniciar o trabalho, analisando como os temas estudados na disciplina eram evidenciados nos relatórios contábeis publicados nos últimos cinco anos.

O contexto apresentado nas instruções da atividade era: "Um investidor da bolsa de valores quer expandir os seus investimentos. Para isso, está avaliando as informações econômicas e financeiras de várias empresas. Você e os principais Chief Financial Officer (CFO) de sua empresa estão preparando o material para apresentarem o contexto da sua empresa e as análises econômicas e financeiras dos últimos 5 anos, comparando-as com as da empresa concorrente". Assim, a partir desse contexto, os estudantes foram informados que cada componente dos grupos deveria assumir um papel, previamente definido pela docente responsável pela disciplina, dentro da companhia aberta: presidente, contador, controller, diretor de marketing ou auditor. A escolha final de cada papel era livre e definida pelo grupo de acordo com o perfil e as habilidades de cada um.

Já os investidores foram representados por docentes e pós-graduandos da universidade objeto de estudo. Participaram da aplicação da técnica, no mínimo, quatro investidores em cada semestre. Ao término do semestre, em data pré-definida, os investidores deveriam escolher uma das companhias abertas apresentadas pelos estudantes para aportar capital.

A realização do trabalho foi dividida em três etapas. A primeira etapa consistia na elaboração de um relatório, observando-se, no mínimo: 1) as características da empresa e do setor de atuação; 2) as políticas contábeis, representatividade de cada conta trabalhada nos tópico estudado na disciplina (disponibilidades operações financeiras, perda estimada com crédito de liquidação duvidosa, provisões, ativos e passivos contingentes e estoques) e a qualidade da evidenciação; 3) o cálculo e a análise de indicadores econômicos e financeiros relacionados aos tópicos estudados; 4) a análise de preço das ações, pagamento de dividendos e argumentação para convencer os investidores a aportar capital nessa empresa. Esse relatório deveria ser preparado de maneira profissional (os estudantes assumindo o papel de membros das empresas) e direcionado para os investidores.

Ademais, os estudantes deveriam analisar tanto os relatórios contábeis da empresa escolhida quanto os da companhia concorrente (que, obrigatoriamente, estava sendo analisada por outro grupo) para fins de comparação e para gerar competição entre os grupos. Assim, desde a primeira etapa da atividade, foi utilizada a técnica role-play.

$\mathrm{Na}$ segunda etapa, os relatórios preparados eram disponibilizados na plataforma web Moodle, em um espaço denominado "Relação com Investidores". Os investidores podiam, na plataforma, fazer questionamentos e tirar dúvidas sobre as informações apresentadas nos relatórios. Assim como na primeira etapa, tanto os estudantes quanto os convidados interagiram assumindo os papéis a eles designados. Na terceira etapa, os estudantes se apresentaram no anfiteatro da universidade. Para a apresentação, os estudantes deveriam assumir os papéis escolhidos (vestuário, postura, temas para a apresentação etc.). Ao término da apresentação de cada grupo, os investidores esclareciam dúvidas sobre os dados apresentados e questionavam sobre perspectivas futuras.

Os relatórios e as postagens no Moodle foram avaliados pela docente responsável pela disciplina, sendo atribuída nota para o grupo, e as apresentações avaliadas pela docente e pelos investidores. Ao final de cada apresentação, os investidores e a professora atribuíram uma nota (de 0 a 10) para cada participante dos grupos. Os grupos com maiores notas nas três etapas eram escolhidos como ganhadores do aporte de capital. 


\subsection{Levantamento da percepção dos estudantes sobre o uso da técnica role-play}

Após as apresentações, porém, antes da divulgação das notas finais da atividade, foi aplicado aos estudantes um questionário adaptado de Weil et al. (2001) e Costa et al. (2018). A idade média dos respondentes é de 17 anos e, aproximadamente, $68 \%$ da amostra é do sexo feminino. Dos 84 estudantes, $61 \%$ não trabalham, o que é explicado pelo fato de a atividade ter sido realizada com estudantes que cursam o primeiro ano do curso e do período integral. Apenas $15 \%$ da amostra são de estudantes que não estavam cursando a disciplina pela primeira vez, ou seja, foram reprovados em semestres anteriores.

O questionário é composto de duas partes, sendo elas: (i) caracterização do respondente e, (ii) avaliação da atividade, com 38 questões. Para tais questões os estudantes deveriam atribuir nota com base na percepção sobre a contribuição da atividade para o processo de ensino-aprendizagem, e nas questões abertas, poderiam expressar suas opiniões de forma livre. Para análise das respostas obtidas com o questionário, utilizou-se, inicialmente, a estatística descritiva univariada. Tendo em vista que a média sofre interferência dos valores extremos, o que pode enviesar a análise de dados, realizou-se o teste de normalidade univariada de Shapiro-Francia, com o intuito de que a distribuição dos dados auxiliasse na interpretação da medida de tendência central que melhor representa cada variável (Fávero \& Belfiore, 2017).

Em seguida, foram agrupadas as 38 questões que tratam da percepção sobre a contribuição da atividade "Contabilidade em Cena" para o processo de aprendizagem conforme as categorias dos domínios cognitivo e afetivo da Taxonomia de Bloom. Assim, foram realizados testes de normalidade em cada grupo e, também, o teste de Wilcoxon para verificar se havia diferença entre as notas atribuídas para cada categoria de forma individualizada, bem como para as categorias agrupadas, em consonância com os estágios do EEEC.

O grau de associação entre as variáveis foi analisado por meio de correlação. Hair, Babin, Money e Samouel (2005) consideram a seguinte variação de coeficientes: $\pm 0,91 \mathrm{a} \pm 1,00$ como associação muito forte; \pm $0,71 \mathrm{a} \pm 0,90$ como alta; $\pm 0,41 \mathrm{a} \pm 0,70$ como moderada; $\pm 0,21 \mathrm{a} \pm 0,40$ como esquema, mas definida; $\mathrm{e} \pm 0,01 \mathrm{a}$ $\pm 0,20$ como leve, ou seja, quase imperceptível.

Para verificar a relação conjunta das categorias da Taxonomia de Bloom, foram realizadas regressões múltiplas que alternavam os grupos de habilidades e categorias como variável dependente, regredindo-se as demais como variáveis independentes. Utilizou-se ainda o procedimento de stepwise para melhoria no ajuste dos modelos, o que resultou na obtenção de subconjuntos de habilidades e categorias úteis para predição de cada dependente.

\subsection{Grupo focal}

Com o objetivo de triangular a análise neste estudo e de coletar evidências específicas sobre a utilidade da técnica role-play no processo de ensino-aprendizagem, foram realizados dois grupos focais, sendo um no segundo semestre de 2017 (2017/2) e outro, no primeiro semestre de 2018 (2018/1). Os estudantes decidiram participar voluntariamente dos grupos focais e manifestaram concordância por meio da assinatura de termo de consentimento.

Os grupos focais foram conduzidos por um moderador que exercia a função de motivador da discussão das questões, podendo fazer interferências, quando necessário. Os principais temas direcionadores dos debates foram: (i) desenvolvimento de habilidades e competências em cada etapa do trabalho (relatório, postagens no Moodle e apresentação); (ii) motivação; (iii) estudo e pesquisa individual ou em grupo; (iv) visão empresarial prática; (v) trabalho em equipe; (vi) dificuldades e limitações; (vii) desempenho na disciplina; e (viii) adequação da técnica para a disciplina. Todos os grupos focais foram gravados, em forma de áudio e vídeo, e transcritos, possibilitando a análise de seu conteúdo e a contraposição com as respostas dos questionários.

Participaram dos grupos focais 23 estudantes, sendo 13 no segundo semestre de 2017 ( 9 estudantes do sexo feminino) e 10, no primeiro semestre de 2018 ( 9 estudantes do sexo feminino), sendo a idade média dos estudantes de cada grupo focal de 20 anos. Para preservar a imagem dos participantes, os nomes dos estudantes foram substituídos pela letra $\mathrm{A}$ seguida do número que representa a ordem em que os questionários respondidos foram incluídos na planilha de compilação dos resultados, por exemplo: "A1, A2, A3, (...), A84". Para os comentários feitos pelos estudantes nos grupos focais, as respostas dos discentes estão identificadas pelo grupo focal do qual fizeram parte [Grupo focal 1 (GF1) e grupo focal 2 (GF2)], seguido da letra A e o número que representa o estudante, da seguinte forma: GF1A1; GF1A2; GF1A3, (...), GF1A23. 


\section{ANÁLISE DOS RESULTADOS}

Os resultados serão discutidos em três subseções. Na primeira serão apresentados os resultados sobre o desenvolvimento de habilidades e competências das categorias cognitivas da Taxonomia de Bloom e a sua relação com os estágios do EEEC. A segunda traz uma proposta de inserção do Domínio Afetivo nos objetivos do EEEC. Na terceira seção são apontadas as dificuldades encontradas pelos estudantes ao longo do processo.

\subsection{Desenvolvimento de habilidades e competências}

A percepção dos estudantes sobre as habilidades e as competências desenvolvidas na atividade "Contabilidade em Cena" é apresentada na Tabela 2, por meio de um ranking baseado na média das notas atribuídas no questionário. Essa Tabela também ilustra os resultados dos testes de normalidade univariados.

Todas as médias obtidas foram superiores a 5 , indicando que os estudantes perceberam a atividade como capaz de desenvolver habilidades e competências no processo de ensino-aprendizagem. Das questões listadas, a "Visão prática do processo de tomada de decisões" foi a que obteve maior média $(9,21)$, seguida por "Responsabilidade pelo próprio aprendizado", com média de 8,89. Ambas as questões, que possuem distribuição não normal, apresentaram nota mediana de 10 , o que sugere que $50 \%$ dos respondentes dessas questões atribuíram nota máxima às mesmas. Sobre a habilidade que lidera o ranking, o estudante A51 considerou que a atividade promoveu "uma visão da realidade e das dificuldades enfrentadas pelos tomadores de decisão" e o estudante A13 considerou que desenvolveu "capacidade de análise de dados e tomada de decisões".

No outro extremo, a Motivação ficou na $38^{\mathrm{a}}$ posição do ranking, com nota média de 7,6. Porém cabe ressaltar que, nesta pesquisa, assim como em Costa et al. (2018), apesar da última colocação do ranking, esse item também possui distribuição não normal, apontando que $50 \%$ dos estudantes atribuíram nota maior que 8 para a "Motivação", o que é positivo do ponto de vista da análise. A maior parte dos estudantes informou ter experimentado uma grande motivação na $3^{\mathrm{a}}$ fase da atividade (a apresentação para os investidores), o que corrobora o resultado da mediana para "Motivação". Sobre esse aspecto, os discentes GF1A4, GF2A9 e GF1A13 concordaram com a opinião de GF1A1: "A última fase foi a melhor parte pra mim (...) a gente tinha que fechar, organizar tudo o que a gente tinha que falar (...) tinha que usar a criatividade porque a gente tinha o objetivo de vencer o concorrente".

A Tabela 2 mostra que as habilidades com maior grau de associação ao estágio 1 do EEEC são: "Integração de diversos assuntos da disciplina", ocupando o $4^{\circ}$ lugar no ranking de habilidades, e "Identificação de dados relevantes", ocupando o $8^{\circ}$ lugar no ranking de habilidades. Sobre a habilidade de integração, GF1A13 destaca que a atividade "mostrou o quão pequeno é (o conteúdo) da disciplina se comparado ao mundo, a contabilidade" e GF2A3, ressalta que "Você tem uma visão ampla de tudo". O estudante GF1A4 informou que, na segunda fase da atividade (postagens no Moodle), desenvolveu a habilidade de "(...) filtrar o que é importante e o que não é", o que corrobora que houve desenvolvimento de habilidades vinculadas ao Estágio 1 do EEEC.

As 38 habilidades e competências foram agrupadas nos Domínios Cognitivo e Afetivo da Taxonomia de Bloom, conforme mostra a Tabela 3. A categoria Avaliação obteve menor média de notas $(8,24)$, seguida do Domínio Afetivo $(8,25)$ e pelas categorias do $1^{\circ}$ estágio do EEEC, que obtiveram nota média de 8,35 , além das demais categorias dos demais estágios, com nota média de 8,5. Essa diferença entre as notas foi testada pelo teste de Wilcoxon, que demonstrou não haver diferença entre o Domínio Afetivo e as categorias do $1^{\circ}$ estágio do EEEC ( $p$-valor de 0,681), o que sugere desenvolvimento equânime dessas categorias entre os estudantes. Por outro lado, o p-valor do Wilcoxon $(<0,05)$ indica diferença entre as categorias do $1^{\circ}$ estágio e as categorias dos estágios posteriores do EEEC.

Esse resultado sugere que, para a amostra analisada, a utilização do role-play: 1) desenvolveu habilidades e competências de todas as categorias cognitivas, além do aspecto afetivo da Taxonomia; 2) desenvolveu de maneira mais proeminente os demais estágios do EEEC (categorias Análise, Síntese e Avaliação), quando comparados com o $1^{\circ}$ estágio (categorias Conhecimento, Compreensão e Aplicação); 3) atingiu os objetivos do EEEC ao desenvolver de maneira positiva (média superior a 8,35) o primeiro estágio, o que possibilita afirmar que a atividade role-play atingiu os objetivos do EEEC. 
Tabela 2. Ranking das habilidades e competências

\begin{tabular}{|c|c|c|c|c|c|c|c|c|c|c|}
\hline Rank & Habilidades e competências & Taxonomia de Bloom & $\mathbf{N}$ & Méd. & D.P. & Mín. & M. & Máx. & $\mathbf{W}^{\prime}$ & $\mathbf{z}$ \\
\hline 1 & Visão prática do processo de tomada de decisões & SÍNTESE & 84 & 9,21 & 1,08 & 6 & 10 & 10 & 0,968 & 0,035 \\
\hline 2 & Responsabilidade pelo próprio aprendizado & DOMÍNIO AFETIVO & 83 & 8,89 & 1,57 & 1 & 10 & 10 & 0,903 & 0,000 \\
\hline 3 & Considerar diferentes perspectivas e usuários & AVALIAÇÃO & 84 & 8,73 & 1,22 & 5 & 9 & 10 & 0,988 & 0,536 \\
\hline 4 & Integração de diversos assuntos da disciplina & COMPREENSÃO & 83 & 8,70 & 1,39 & 5 & 9 & 10 & 0,980 & 0,198 \\
\hline 5 & Visão do funcionamento de uma empresa & SÍNTESE & 84 & 8,70 & 1,59 & 1 & 9 & 10 & 0,917 & 0,000 \\
\hline 6 & Interpretação das demonstrações financeiras & ANÁLISE & 83 & 8,66 & 1,34 & 5 & 9 & 10 & 0,983 & 0,274 \\
\hline 7 & Relacionar teoria e prática & SÍNTESE & 84 & 8,62 & 1,47 & 1 & 9 & 10 & 0,898 & 0,000 \\
\hline 8 & Identificação de dados relevantes & CONHECIMENTO & 84 & 8,62 & 1,40 & 4 & 9 & 10 & 0,985 & 0,365 \\
\hline 9 & Interpretação & ANÁLISE & 84 & 8,61 & 1,20 & 5 & 9 & 10 & 0,989 & 0,603 \\
\hline 10 & Aplicação do conhecimento & SÍNTESE & 84 & 8,60 & 1,43 & 4 & 9 & 10 & 0,983 & 0,283 \\
\hline 11 & Conhecimento técnico & COMPREENSÃO & 84 & 8,60 & 1,55 & 4 & 9 & 10 & 0,980 & 0,182 \\
\hline 12 & Análise & ANÁLISE & 84 & 8,57 & 1,34 & 5 & 9 & 10 & 0,995 & 0,950 \\
\hline 13 & Trabalho em equipe & CONHECIMENTO & 83 & 8,55 & 1,95 & 0 & 9 & 10 & 0,906 & 0,000 \\
\hline 14 & Sumarizar informações & COMPREENSÃO & 84 & 8,52 & 1,38 & 5 & 9 & 10 & 0,978 & 0,133 \\
\hline 15 & Criatividade & DOMÍNIO AFETIVO & 83 & 8,52 & 1,40 & 4 & 9 & 10 & 0,988 & 0,549 \\
\hline 16 & Avaliar ideias & ANÁLISE & 84 & 8,49 & 1,65 & 1 & 9 & 10 & 0,904 & 0,000 \\
\hline 17 & Considerar várias soluções & AVALIAÇÃO & 84 & 8,49 & 1,60 & 3 & 9 & 10 & 0,957 & 0,008 \\
\hline 18 & Comunicação escrita & CONHECIMENTO & 83 & 8,43 & 1,73 & 0 & 9 & 10 & 0,857 & 0,000 \\
\hline 19 & Pensamento crítico & ANÁLISE & 84 & 8,42 & 1,56 & 3 & 9 & 10 & 0,980 & 0,197 \\
\hline 20 & Distinguir fatos de opiniões & APLICAÇÃO & 84 & 8,42 & 1,28 & 5 & 8 & 10 & 0,992 & 0,804 \\
\hline 21 & Habilidades de pesquisa & DOMÍNIO AFETIVO & 83 & 8,39 & 1,85 & 2 & 9 & 10 & 0,928 & 0,000 \\
\hline 22 & Participação ativa & DOMÍNIO AFETIVO & 84 & 8,37 & 1,73 & 1 & 9 & 10 & 0,932 & 0,001 \\
\hline 23 & Organização de informações & CONHECIMENTO & 84 & 8,30 & 1,45 & 3 & 8 & 10 & 0,983 & 0,296 \\
\hline 24 & Julgamento & APLICAÇÃO & 84 & 8,27 & 1,70 & 2 & 9 & 10 & 0,975 & 0,097 \\
\hline 25 & Estudar os conteúdos da disciplina & DOMÍNIO AFETIVO & 83 & 8,27 & 1,73 & 3 & 9 & 10 & 0,988 & 0,573 \\
\hline
\end{tabular}

Fonte: elaborada pelas autoras.

Nota: $\mathrm{N}=\mathrm{n}^{\circ}$ de observações; Méd = média; $\mathrm{D} . \mathrm{P}=$ desvio padrão; Mín = valor mínimo; $\mathrm{M}=50 \%$; Máx= valor máximo; W’= teste de normalidade univariada de Shapiro-Francia; $\mathrm{z}=$ p-valor do teste de Shapiro-Francia 
Tabela 2. Ranking das habilidades e competências (continuação)

\begin{tabular}{|c|c|c|c|c|c|c|c|c|c|c|}
\hline Rank & Habilidades e competências & Taxonomia de Bloom & $\mathbf{N}$ & Média & D.P. & Mín. & Mediana & Máx. & $\mathbf{W}^{\prime}$ & $\mathbf{z}$ \\
\hline 26 & Pensar conceitualmente & ANÁLISE & 84 & 8,25 & 1,39 & 4 & 8 & 10 & 0,992 & 0,788 \\
\hline 27 & Habilidade de ouvir & DOMÍNIO AFETIVO & 84 & 8,24 & 1,95 & 1 & 9 & 10 & 0,959 & 0,010 \\
\hline 28 & Resolução de problemas & APLICAÇÃO & 84 & 8,23 & 1,52 & 2 & 8 & 10 & 0,969 & 0,041 \\
\hline 29 & Síntese & SÍNTESE & 84 & 8,20 & 1,45 & 5 & 8 & 10 & 0,996 & 0,990 \\
\hline 30 & Consolidação de conhecimentos prévios & COMPREENSÃO & 84 & 8,13 & 1,77 & 4 & 8 & 10 & 0,978 & 0,143 \\
\hline 31 & Lidar com incerteza e ambiguidade & AVALIAÇÃO & 84 & 8,13 & 1,54 & 3 & 8 & 10 & 0,976 & 0,100 \\
\hline 32 & Tomada de decisões com informações incompletas & AVALIAÇÃO & 84 & 8,11 & 1,73 & 1 & 8 & 10 & 0,952 & 0,004 \\
\hline 33 & Persuasão & CONHECIMENTO & 84 & 8,10 & 1,80 & 0 & 8 & 10 & 0,922 & 0,000 \\
\hline 34 & Identificação de problemas & CONHECIMENTO & 84 & 8,08 & 1,50 & 4 & 8 & 10 & 0,992 & 0,795 \\
\hline 35 & Questionamentos pertinentes & DOMÍNIO AFETIVO & 84 & 8,01 & 1,65 & 2 & 8 & 10 & 0,959 & 0,011 \\
\hline 36 & Liderança & DOMÍNIO AFETIVO & 83 & 7,98 & 2,05 & 1 & 8 & 10 & 0,888 & 0,000 \\
\hline 37 & Oratória e Comunicação Verbal & CONHECIMENTO & 83 & 7,88 & 2,29 & 1 & 8 & 10 & 0,901 & 0,000 \\
\hline 38 & Motivação & DOMÍNIO AFETIVO & 84 & 7,60 & 2,37 & 1 & 8 & 10 & 0,936 & 0,001 \\
\hline
\end{tabular}

Fonte: elaborada pelas autoras.

Nota: $\mathrm{N}$ = n⿳亠口冋 de observações; Méd = média; D.P = desvio padrão; Mín = valor mínimo; M = 50\%; Máx= valor máximo; W’= teste de normalidade univariada de Shapiro-Francia; $\mathrm{z}=$ p-valor do teste de Shapiro-Francia

Tabela 3. Estatística descritiva das categorias da Taxonomia de Bloom e resultados do teste de Wilcoxon

\begin{tabular}{|c|c|c|c|c|c|c|c|c|c|c|c|}
\hline \multirow{2}{*}{ EECC } & Taxonomia de Bloom & $\mathbf{N}$ & Média & D. $P$ & Mínimo & Máximo & Média & $\mathbf{z}^{\prime}$ & p-valor' & z" & p-valor" \\
\hline & Domínio afetivo & 83 & 8,25 & 1,19 & 4,87 & 10,00 & 8,25 & & & & \\
\hline \multirow{3}{*}{$1^{\circ}$ estágio EEEC } & Conhecimento & 84 & 8,29 & 1,26 & 3,83 & 10,00 & & & & & \\
\hline & Compreensão & 83 & 8,44 & 1,12 & 5,20 & 10,00 & 8,35 & 0,41 & 0,681 & & \\
\hline & Aplicação & 84 & 8,31 & 1,18 & 5,67 & 10,00 & & & & & \\
\hline \multirow{3}{*}{ Demais estágios EEEC } & Análise & 83 & 8,50 & 1,03 & 5,67 & 10,00 & & & & & \\
\hline & Síntese & 84 & 8,77 & 0,95 & 6,00 & 10,00 & 8,50 & & & $-2,17$ & 0,007 \\
\hline & Avaliação & 84 & 8,24 & 1,23 & 4,00 & 10,00 & & & & & \\
\hline
\end{tabular}

Fonte: elaborada pelas autoras.

Nota: $\mathrm{N}=\mathrm{n}^{\circ}$ de observações; D.P= desvio padrão; $\mathrm{z}^{\prime}=$ estatística do teste de Wilcoxon entre o $1^{\circ}$ estágio EEEC (Conhecimento, Compreensão e Aplicação) e Domínio afetivo; $\mathrm{z}^{\prime \prime}=$ estatística do teste de Wilcoxon entre $1^{\circ}$ estágio EEEC e demais categorias do Domínio Cognitivo (Análise, Sintese e Avaliação). 
A Tabela 3 demonstra ainda as médias individualizadas das categorias do Domínio Cognitivo. É possível notar que as maiores médias estão nas categorias Síntese, Análise e Compreensão, com notas de 8,77, 8,50 e 8,44, respectivamente. Acredita-se que as notas de Síntese e Análise tenham sido fundamentais para as diferenças encontradas entre o grupo $1^{\circ}$ estágio do EEEC e o grupo que compreende os demais estágios do EEEC. Para testar tal suposição, realizou-se o teste de Wilcoxon com todas as categorias da Taxonomia de Bloom para verificar se as notas são estatisticamente diferentes entre si. Os resultados são apresentados na Tabela 4.

Tabela 4. Teste de Wilcoxon entre as categorias da Taxonomia de Bloom

\begin{tabular}{|c|c|c|c|c|c|c|c|}
\hline \multirow{2}{*}{$\begin{array}{l}\text { Taxonomia de } \\
\text { Bloom }\end{array}$} & \multicolumn{7}{|c|}{ Prob $>|z|$} \\
\hline & Conhecimento & Compreensão & Aplicação & Análise & Síntese & Avaliação & $\begin{array}{l}\text { Domínio } \\
\text { afetivo }\end{array}$ \\
\hline Conhecimento & 1 & & & & & & \\
\hline Compreensão & 0,1408 & 1 & & & & & \\
\hline Aplicação & 0,6015 & 0,2059 & 1 & & & & \\
\hline Análise & 0,0498 & 0,2430 & 0,0079 & 1 & & & \\
\hline Síntese & 0,0000 & 0,0001 & 0,0000 & 0,0064 & 1 & & \\
\hline Avaliação & 0,3134 & 0,1826 & 0,7069 & 0,0203 & 0,0000 & 1 & \\
\hline Domínio afetivo & 0,4102 & 0,1434 & 0,9060 & 0,0026 & 0,0000 & 0,9674 & 1 \\
\hline
\end{tabular}

Fonte: elaborada pelas autoras.

Os resultados demonstram que as notas para Síntese e Análise foram fundamentais para as diferenças encontradas entre o grupo $1^{\circ}$ estágio do EEEC e o grupo que compreende os demais estágios do EEEC. Especificamente, Sintese se mostrou diferente de Domínio Afetivo, Avaliação, Análise, e de todas as categorias do $1^{\circ}$ estágio do EEEC, quais sejam: Conhecimento, Compreensão e Aplicação. Tal resultado sugere que a utilização do role-play desenvolveu de forma marcante a habilidade de Síntese, frente às habilidades de conhecimento, compreensão e aplicação.

Infere-se, portanto, que a aplicação da técnica role-play possibilitou o desenvolvimento de habilidades e competências esperadas para o estágio 1 do EEEC (Conhecimento, Compreensão e Aplicação) e, admiravelmente, também auxiliou no desenvolvimento de habilidades e competências das demais categorias cognitivas da Taxonomia. Conclui-se que, desde o início do curso de Ciências Contábeis, especificamente, nas disciplinas introdutórias de contabilidade, é possível que o estudante desenvolva habilidades e competências de julgamento, pensamento crítico e o pensar conceitualmente (categorias mais altas da Taxonomia de Bloom), conforme preconiza o EEEC.

Destaca-se ainda que a maior parte das habilidades abarcadas na categoria Síntese foram também aquelas que se destacaram nos relatos dos estudantes nas questões abertas e nos grupos focais: considerar diferentes perspectivas e usuários ( $3^{\circ}$ lugar do ranking): "uma coisa interessante do trabalho foi você conseguir analisar os dois lados da moeda (o do proprietário e o do investidor) (...) você consegue ver o que tem de bom e o que tem de ruim (na empresa)" (GF1A13); visão do funcionamento de uma empresa (5 lugar no ranking): "realmente, é uma contabilidade em cena porque, durante o semestre inteiro, a gente teve que viver os números das empresas" (GF2A3). "Essa primeira parte é interessante pra quem tinha dúvida em relação à profissão. Eu mesma tinha dúvida em relação à profissão, mas analisar o demonstrativo e entrar realmente no mundo da contábeis, realmente, reforçou que é isso que eu quero" (GF1A5); relacionar teoria e prática (7 lugar no ranking): "Eu trabalho há algum tempo nessa área mais gerencial e, nessa minha longa jornada em contábeis (graduação), eu nunca tinha visto isso de a gente aprender uma coisa em sala e colocar ela em prática de forma semelhante ao que a gente faz no trabalho no dia a dia" (GF1A8).

Além disso, com relação à categoria Análise, o estudante GF1A1 declarou: "a gente passa a trabalhar muito a lógica, pra você ver a questão dos estoques. Pra mim, era vantagem ter muito estoque, mas aí você vai pensando: e, se eu fosse o investidor, eu não iria querer que a minha empresa tivesse tanto estoque assim porque, se ela está com muito estoque, é porque (a mercadoria) não está girando". Percebe-se que o estudante foi capaz de construir pontes cognitivas por meio da acumulação dos conceitos assimilados em sala de aula com o conhecimento prático promovido pelo role-play, o que resultou em análise e capacidade de julgamento sobre a temática estoques na prática empresarial. 


\subsection{Inserção do Domínio Afetivo no EEEC}

Outro ponto positivo do uso da técnica role-play, na percepção dos estudantes, foi o desenvolvimento de habilidades e competências do Domínio Afetivo da Taxonomia de Bloom. Especificamente, sobre a habilidade Responsabilidade pelo próprio aprendizado, os estudantes destacaram ter melhorado os seus processos de planejamento e organização das atividades.

O respondente $\mathrm{A} 64$ destaca que foi um desafio o "controle do tempo destinado à realização das atividades, conciliar as demais matérias e as matérias da disciplina com a realização do trabalho" e A73 complementou que a atividade "melhora a capacidade de lidar com datas e horários, o que é crucial dentro de uma empresa". Para a habilidade Participação ativa, A60 e A21 destacam que desenvolveram "proatividade" e GF2A6 complementa: "eu me peguei pesquisando até coisas que não estava perguntando só pra saber mais sobre a empresa". Percebese, assim, que a atividade fez com que os estudantes se tornassem mais ativos no processo de ensino-aprendizagem.

Para verificar as interações existentes entre as categorias dos domínios Cognitivo e Afetivo, foram realizadas análise bivariada (Tabela 5) e multivariada (Tabela6).

Tabela 5. Correlação entre as categorias da Taxonomia de Bloom

\begin{tabular}{llllllll}
\hline $\begin{array}{l}\text { Taxonomia de } \\
\text { Bloom }\end{array}$ & Conhecimento & Compreensão & Aplicação & Análise & Síntese & Avaliaçãoo & $\begin{array}{l}\text { Domínio } \\
\text { afetivo }\end{array}$ \\
\hline Conhecimento & 1 & & & & & & \\
Compreensão & 0,6546 & 1 & & & & & \\
Aplicação & 0,7057 & 0,6642 & 1 & & & & \\
Análise & 0,7266 & 0,7883 & 0,7711 & 1 & & & \\
Síntese & 0,6465 & 0,6535 & 0,6232 & 0,6589 & 1 & & \\
Avaliação & 0,6599 & 0,6247 & 0,5692 & 0,6862 & 0,4837 & 1 & \\
Domínio afetivo & 0,7631 & 0,7423 & 0,6644 & 0,8084 & 0,6385 & 0,6596 & 1 \\
\hline
\end{tabular}

Fonte: elaborada pelas autoras.

Todas as categorias relacionam-se positivamente de forma moderada a alta entre si, tendo em vista que os coeficientes foram acima de 0,5 (Tabela 5). O sinal positivo indica que o comportamento das habilidades e competências não é inverso, ou seja, o desenvolvimento de uma habilidade e competência não prejudica o desenvolvimento de outra.

O Domínio Afetivo, que envolve o desenvolvimento da área emocional e afetiva, incluindo comportamento, atitude, responsabilidade, entre outros (Ferraz \& Belhot, 2010), possui alta correlação com as categorias Análise, Compreensão e Conhecimento. Esses resultados demonstram que os estudantes que desenvolveram alto Domínio Afetivo com a aplicação da atividade apresentaram comportamento semelhante com as capacidades de análise, compreensão e conhecimento, e vice-versa (Tabela 5). Os pares Análise e Aplicação, Análise e Compreensão, Análise e Conhecimento, e Aplicação e Conhecimento também apresentaram coeficientes de correlação considerados altos, conforme os graus de associação mencionados por Hair et al. (2005).

A Tabela 6 apresenta os resultados obtidos na análise multivariada, os quais demonstram que o desenvolvimento de cada uma das habilidades está associado ao desenvolvimento simultâneo de outras variáveis. Percebe-se que, no $1^{\circ}$ estágio do EEEC, em específico, $67,6 \%\left(\mathrm{R}^{2}\right)$ do desenvolvimento da categoria Conhecimento, aproximadamente, estão associados ao desenvolvimento do Domínio Afetivo e das categorias de Avaliação e Aplicação. A Compreensão, por sua vez, tem cerca de $67,3 \%\left(\mathrm{R}^{2}\right)$ do seu desenvolvimento atrelado ao desenvolvimento do Domínio Afetivo, Síntese e Análise, tendo a Aplicação, aproximadamente, $64 \%$ de seu desenvolvimento associado ao Conhecimento e Análise. 
Tabela 6. Relações conjuntas entre as categorias da Taxonomia de Bloom

\begin{tabular}{|c|c|c|c|c|c|c|}
\hline & $\begin{array}{l}\text { Variáveis } \\
\text { independentes }\end{array}$ & Coef & $\mathbf{t}$ & $\mathbf{P}>|\mathbf{t}|$ & Prob $>$ F & $\mathbf{R}^{2}$ \\
\hline \multirow{4}{*}{ Conhecimento } & Domínio afetivo & 0.398 & 4.36 & 0.000 & \multirow{4}{*}{0.000} & \multirow{4}{*}{0.676} \\
\hline & Avaliação & 0.187 & 2.33 & 0.022 & & \\
\hline & Aplicação & 0.288 & 3.47 & 0.001 & & \\
\hline & Constante & 1.069 & 1.86 & 0.067 & & \\
\hline \multirow{4}{*}{ Compreensão } & Domínio afetivo & 0.233 & 2.16 & 0.034 & \multirow{4}{*}{0.000} & \multirow{4}{*}{0.673} \\
\hline & Síntese & 0.229 & 2.16 & 0.034 & & \\
\hline & Análise & 0.509 & 4.00 & 0.000 & & \\
\hline & Constante & 0.169 & 0.23 & 0.815 & & \\
\hline \multirow{3}{*}{ Aplicação } & Análise & 0.632 & 5.56 & 0.000 & \multirow{3}{*}{0.000} & \multirow{3}{*}{0.639} \\
\hline & Conhecimento & 0.330 & 3.13 & 0.002 & & \\
\hline & Constante & 0.208 & 0.30 & 0.765 & & \\
\hline \multirow{4}{*}{ Análise } & Domínio afetivo & 0.323 & 4.47 & 0.000 & \multirow{4}{*}{0.000} & \multirow{4}{*}{0.786} \\
\hline & Aplicação & 0.285 & 4.41 & 0.000 & & \\
\hline & Compreensão & 0.268 & 3.53 & 0.001 & & \\
\hline & Constante & 1.210 & 3.53 & 0.007 & & \\
\hline \multirow{3}{*}{ Síntese } & Conhecimento & 0.324 & 3.68 & 0.000 & \multirow{3}{*}{0.000} & \multirow{3}{*}{0.511} \\
\hline & Compreensão & 3.261 & 3.87 & 0.000 & & \\
\hline & Constante & 3.261 & 5.32 & 0.000 & & \\
\hline \multirow{3}{*}{ Avaliação } & Conhecimento & 0.377 & 3.03 & 0.003 & \multirow{3}{*}{0.000} & \multirow{3}{*}{0.526} \\
\hline & Análise & 0.522 & 3.88 & 0.000 & & \\
\hline & Constante & 0.701 & 0.86 & 0.393 & & \\
\hline \multirow{4}{*}{ Domínio afetivo } & Análise & 0.463 & 3.78 & 0.000 & \multirow{4}{*}{0.000} & \multirow{4}{*}{0.734} \\
\hline & Conhecimento & 0.358 & 3.89 & 0.000 & & \\
\hline & Compreensão & 0.215 & 2.12 & 0.037 & & \\
\hline & Constante & -0.458 & -0.76 & 0.447 & & \\
\hline
\end{tabular}

Fonte: elaborada pelas autoras.

Nota: Coef. $=$ coeficientes, $\mathrm{t}=$ estatística do teste $\mathrm{t} ; \mathrm{P}>|\mathrm{t}|=\mathrm{p}$-valor do teste $\mathrm{t}$; Prob $>\mathrm{F}=\mathrm{p}$-valor do teste $\mathrm{F} ; \mathrm{R}^{2}=$ coeficiente de determinação.

Esses resultados podem indicar que, embora o EEEC aponte somente o Conhecimento, a Compreensão e a Aplicação como habilidades do $1^{\circ}$ estágio, o desenvolvimento dessas habilidades não se dá de forma isolada das habilidades dos estágios posteriores. Por exemplo, o Domínio Afetivo, apesar de não estar contemplado na EEEC, pode se mostrar fundamental para o desenvolvimento de duas das habilidades do $1^{\circ}$ estágio: Conhecimento e Compreensão. No entanto, nota-se que essa relação não é unidirecional, pois o Conhecimento e a Compreensão também estão associados ao desenvolvimento do Domínio Afetivo. Além disso, as capacidades de Análise, Conhecimento e Compreensão explicam em 73\% o Domínio Afetivo dos estudantes. Esse resultado indica que os estudantes que analisam, compreendem e adquirem conhecimento conseguem desenvolver melhor as habilidades relacionadas aos sentimentos e posturas.

Os achados ainda corroboram o exposto por Wells e Tarca (2014). Segundo eles, no estágio 1 o estudante desenvolveria as habilidades relacionadas às categorias do Domínio Cognitivo e, nos estágios 2 e 3 , haveria um aprofundamento nessas habilidades. 


\subsection{Aspectos Dificultadores}

De forma geral, a aplicação da atividade "Contabilidade em Cena" foi positivamente avaliada e recomendada para aplicação às futuras turmas de Contabilidade Introdutória II. As principais dificuldades apontadas pelos estudantes foram: a complexidade e extensão da atividade, a falta de tempo e a consequente dificuldade para conciliar as atividades com os demais conteúdos estudados no semestre e a falta de conhecimento sobre todos os conteúdos abordados na atividade. Por exemplo, o estudante A22 informou: "A atividade é ótima, mas o grande problema foi a inserção de assuntos não aprendidos, fazendo com que perdêssemos o foco da matéria do semestre, o que demandou tempo de pesquisas e atrapalhou outras disciplinas. Pra quem trabalha, é muito puxado". Como sugestões de melhoria na aplicação, GF1A7 sugere que o trabalho seja interdisciplinar e que os professores das disciplinas mais avançadas reapliquem a atividade para testar o avanço das habilidades dos estudantes (GF1A4).

Outra dificuldade enfrentada pelos estudantes foi a timidez, sendo a atividade importante para a sua superação: "a terceira parte foi boa pra gente sair um pouco da zona de conforto. Eu, por exemplo, sou muito tímido, e apresentar, pra mim, em público é muito difícil. Quanto antes a gente tiver esse tipo de experiência, melhor pra gente" (GF1A10); "Gostei muito do trabalho, ajudou muito a desenvolver técnicas de comunicação verbal. Por ser muito tímida, foi minha maior dificuldade. Mas acho essencial, pois sei que precisarei muito ao longo do curso" (A41).

Essas dificuldades podem ter relação com o fato de que grande parte do processo de aprendizagem na Instituição de Ensino em que foi aplicada essa atividade ainda é pautada na metodologia tradicional de ensino, tornando a atividade um desafio para os estudantes. Além disso, a atividade poderia ser desenvolvida de maneira interdisciplinar com a disciplina de Gestão Empresarial que é oferecida no mesmo semestre, o que poderia reduzir a dificuldade em conciliar o tempo entre as disciplinas e, também, a complexidade.

\section{CONSIDERAÇÕES FINAIS}

O uso do role-play na disciplina de Contabilidade Introdutória II (estágio 1) se mostrou relevante, segundo a percepção dos estudantes que participaram do levantamento e dos grupos focais, para o desenvolvimento de habilidades e competências de todas as categorias do Domínio Cognitivo da Taxonomia de Bloom. O esperado, de acordo com o EEEC (Costa et al., 2018), era que fossem desenvolvidas habilidades e competências das três primeiras categorias do Domínio Cognitivo (Conhecimento, Compreensão e Aplicação), uma vez que os estudantes estão ainda no primeiro ano do curso, cursando a segunda disciplina de contabilidade (estágio 1 do EEEC). No entanto, de maneira positiva, a técnica role-play auxiliou os estudantes a atingirem também as categorias mais altas da Taxonomia (Análise, Sintese e Avaliação), o que demonstra a eficácia dessa técnica nas disciplinas iniciais do curso.

A aplicação do role-play se mostrou efetiva no alcance dos objetivos propostos pelo EEEC para o estágio 1. Por meio do uso dessa técnica, foi possível abranger todas as categorias do Domínio Cognitivo, no que tange aos estágios 1, 2 e 3 do EEEC. As habilidades e competências mais desenvolvidas são aquelas ligadas à visualização do ambiente real de tomada de decisões e à capacidade de lidar com incertezas e informações incompletas. As maiores ocorrências de habilidades e competências aprimoradas estão localizadas nas mais altas categorias do Domínio Cognitivo , especialmente, a de Síntese, o que pode denotar a efetividade dessa técnica na consecução dos objetivos de aprendizagem e que, no início do curso, é possível desenvolver atividades que possam atingir essas categorias mais altas.

Os estudantes consideraram a atividade envolvendo o role-play adequada para o ensino da disciplina Contabilidade Introdutória II. As categorias do Domínio Cognitivo interagem entre si e com o Domínio Afetivo, sugerindo simultaneidade entre elas. O Domínio Afetivo auxilia no desenvolvimento das categorias cognitivas da Taxonomia e vice-versa, portanto deveria ser contemplado no EEEC.

Os resultados são correlatos aos de estudos que apontam para a efetividade de metodologias ativas, como o role-play (Kern, 2001, Souza et al., 2013, Souza \& Casa Nova, 2017) e casos para ensino (Weil et al., 2001, Hodgdon et al., 2011, Bonnier et al., 2013, Coetzee \& Schmulian, 2013, Hilton \& Johnstone, 2013, Jackling et al., 2013) para o desenvolvimento de habilidades e competências, especialmente, em cursos de Ciências Contábeis.

Os resultados deste estudo podem ser úteis para todos os envolvidos no processo de ensino-aprendizagem acerca das IFRS, quais sejam: instituições de ensino superior, professores, estudantes, gestores de empresas, reguladores e normatizadores. 
O uso do role-play se mostrou útil para o desenvolvimento de habilidades e competências necessárias para a formação do profissional da área contábil, podendo ser recomendado o uso dessa técnica nas disciplinas iniciais de contabilidade com o intuito de proporcionar aos estudantes uma visão da realidade empresarial e do processo de tomada de decisões.

Além disso, os resultados podem ser úteis para o IASB no aprimoramento do EEEC, ao considerar que: todas as categorias do Domínio Cognitivo podem ser desenvolvidas no estágio 1, sugerindo que o que distingue os estágios do EEEC é o nível de aprofundamento nas categorias da Taxonomia e não a hierarquização; e o Domínio Afetivo deve ser contemplado no EEEC por estar relacionado com a postura ativa do estudante no processo de ensino-aprendizagem.

A amostra da pesquisa foi selecionada por conveniência e o estudo é do tipo exploratório-qualitativo, o que impossibilita a generalização dos resultados. Também não foram controladas no estudo características sociais, culturais e socioeconômicas dos estudantes, o que representa uma outra limitação do estudo, uma vez que a aprendizagem dos estudantes pode estar relacionada com esses aspectos. Outra limitação do estudo é a subjetividade envolvida nas respostas dadas pelos estudantes (percepção), porém o grupo focal teve o objetivo de minimizar esse aspecto.

Pesquisas futuras podem avaliar o uso dessa técnica nos estágios 2 e 3 do EEEC, bem como analisar a efetividade de outras metodologias ativas no ensino das IFRS. Outra sugestão é a realização de grupos de controle para comparação da eficácia da técnica, podendo os pesquisadores também buscarem mais evidências da necessidade de contemplação do Domínio Afetivo no EEEC. Sugere-se também incluir avaliações diagnósticas e somativas para incorporar experiências a priori dos estudantes e variáveis sociais, econômicas e culturais.

\section{REFERÊNCIAS}

Armstrong, E. K. (2003). Applications of role-playing in tourism management teaching: An evaluation of a learning method. Journal of Hospitality, Leisure, Sport and Tourism Education, 2(1), p. 5-16. DOI: https:// doi.org/10.3794/johlste.21.24.

Costa, P. S., Gomes, G. S., Braunbeck, G. O., Santana, M. E. G. (2018). Um safari no Brasil: evidências sobre o ensino baseado na estrutura conceitual. Revista Contabilidade \& Finanças, 29(76), p. 129-147. DOI: https:// doi.org/10.1590/1808-057x201804760.

Fávero, L. P., Belfiore, P. (2017). Manual de análise de dados: estatística e modelagem multivariada com Excel ${ }^{\circledR}$, SPSS ${ }^{\circledR}$ e Stata ${ }^{\circledR}$. Rio de Janeiro: Elsevier Brasil.

Ferraz, A. P. C. M., Belhot, R. (2010). Taxonomia de Bloom: revisão teórica e apresentação das adequações do instrumento para definição de objetivos instrucionais. Gest. Prod., 17(2), p. 421-431. DOI: https://doi. org/10.1590/S0104-530X2010000200015.

Geiger, M. A., Ogilby, S. M. (2000). The first course in accounting: Students' perceptions and their effect on the decision to major in accounting. Journal of Accounting Education, 18(2), p. 63-78. DOI: https://doi. org/10.1016/S0748-5751(00)00011-7.

Goeld, P. A. (2013). IFRS framework-based case study: Barrick Gold Corporation - Goodwill for GOLD. Journal of Accounting Education, 31(4), P. 383-399. DOI: https://doi.org/10.1016/j.jaccedu.2013.07.003.

Hair, J., Babin, B., Money, A., Samouel, P. (2005). Fundamentos de métodos de pesquisa em administração. Trad. Lene Belon Ribeiro. Porto Alegre: Bookman.

Kern, B. (2001). Using role play simulation and hands-on models to enhance students' learning fundamental accounting concepts. Journal of the Scholarship of Teaching and Learning, p.8-24.

Mactavish, C., Moore, J. (2016). Artisan Flowers Inc.: A Framework-Based Approach to IFRS Leasing Standards. Accounting Perspectives, 15(2), p.131-138. DOI: https://doi.org/10.1111/1911-3838.12092.

Masetto, M. T. (2003). Competência pedagógica do professor universitário. São Paulo: Summus Editorial.

Mclaughlan, R. G., Kirkpatrick, D. (2004). Online roleplay: Design for active learning. European Journal of Engineering Education, 29(4), p. 477-490. DOI: https://doi.org/10.1080/03043790410001716293.

Oliveira, L. A., Costa, P. S., Botinha, R. A., Tavares, M. (2016). Desempenho nas disciplinas introdutórias de contabilidade: base para o sucesso do estudante no curso de Ciências Contábeis. Revista Mineira de Contabilidade, 17(2), p. 72-83. 
Richardson, J. D., Kleiner, B. H. (1992). The relevant effectiveness of different training and development methodologies. Management Research News, 15(10), p. 23-26. DOI: https://doi.org/10.1108/eb028264.

Souza, A. C. M., Souza, R. B. D. L., Souza, L. N. (2013). Habilidades e aprendizagem desenvolvidas com a inserção do role-play no ensino de contabilidade: uma visão discente. ConTexto, 13(25), p. 45-54.

Souza, L. N., Casa Nova, S. P C. (2017). O role-play (jogo de papeis) aplicado no ensino e aprendizagem. In: Leal, E. A., Miranda, G. J., Casa Nova, S. P. D. C. (ORGS.). Revolucionando a sala de aula: como envolver o estudante aplicando técnicas de metodologias ativas de aprendizagem. São Paulo: Atlas.

Weil, S., Oyelere, P., Yeoh, J., Firer, C. (2001). A study of students' perceptions of the usefulness of case studies for the development of finance and accounting-related skills and knowledge. Accounting Education, 10(2), p. 123-146. DOI: https://doi.org/10.1080/09639280110081642.

Wells, M. J. C. (2011). Framework-based approach to teaching principles-based accounting standards. Accounting Education: an International Journal, 20(4), p. 303-316. DOI: https://doi.org/10.1080/09639284.2011.5691 28.

Wells, M. J. C. (2014). Tarca, A. Estágio 3 - Ativos não financeiros: estudo de caso da Open Safari. London: IFRSF Publications Department.

\section{Como citar este artigo}

Costa, P. de S., Ávila, J. R. de M. S., Santos, D. V. dos, \& Cruz, F. P. da. (2020). Role-Play: desenvolvendo habilidades e competências do Ensino Embasado na Estrutura Conceitual. Revista de Contabilidade e Organizações, 14:e164092. DOI: http://dx.doi.org/10.11606/issn.1982-6486.rco.2020.164092 